\title{
ESTUDIO SOBRE EL URBANISMO MODERNO: ADOLFO BLANCO Y PÉREZ DEL CAMINO, PENSIONADO POR LA JAE EN 1927*
}

\author{
María DíEz IBARGoITIA
}

\begin{abstract}
Adolfo Blanco realizó uno de los primeros estudios dentro de la disciplina urbanística. La obra analizada contiene 66 láminas (entre planos y dibujos) de los ensanches de las ciudades del Norte de África y Europa.

Palabras clave: Urbanismo siglo XX; Adolfo Blanco; Junta de Ampliación de Estudios; Real Academia de EspañaRoma.
\end{abstract}

\section{A STUDY OF MODERN URBAN PLANNING: ADOLFO BLANCO Y PÉREZ DEL CAMINO, FELLOW OF THE JAE, 1927}

Adolfo Blanco carried out one of the first studies within the discipline of urban planning. The work analyzed includes 66 plates (plans and drawings) for the expansion of cities in North Africa and Europe.

Key words: $20^{\text {th }}$ Century Urbanism; Adolfo Blanco; Junta de Ampliación de Estudios; Spanish Academy-Rome.

La documentación encontrada recientemente en el archivo familiar de Adolfo Blanco y Pérez del Camino, contiene ciento sesenta y seis láminas, entre planos de los ensanches de las principales ciudades del Norte de África y Europa, y dibujos de las nuevas tipologías de vivienda social de los años veinte ${ }^{1}$. Se trata de uno de los primeros estudios realizados de la disciplina urbanística, llevado a cabo gracias a la pensión concedida al arquitecto por la Junta de Ampliación de Estudios en Enero de 1927 y por la Academia de Bellas Artes de España en Roma (1923-1927).

Adolfo Blanco había nacido en Madrid en 1897. Fue hijo de Rufino Blanco, uno de los grandes impulsores de la Pedagogía moderna. De su padre, heredó la vocación pedagógica y a ella se dedicó durante toda su vida, haciéndola compatible con la práctica de su profesión. Los años que pasó en la Escuela de Arquitectura de Madrid como estudiante fueron determinantes para su formación y trayectoria posterior. El afán por abrirse a Europa, por penetrar en la tradición española y su conservación, le permitió, finalizados sus estudios, ganar el premio de la pensión en Roma con un proyecto Gran templo en la pradera alta dedicado a San Isi$d r o^{2}$.

Fue nombrado pensionado de la Academia Española de Bellas Artes en Roma e1 9 de octubre de 1923, para perfeccionar sus estudios periodo que duró cuatro años, obteniendo a su término seis meses de prórroga como premio a la Calificación Honorífica que mereció su último proyecto Palacio y Monumento de las Bellas Artes, de acuerdo a lo establecido en el Reglamento de la Academia (fig. 1).

En el mes de noviembre estaba ya en Roma y allí fue acogido, junto con Fernando García Mercadal, por Emilio Moya Lledó que había llegado a la Academia un año antes. Durante el primer y segundo año de pensionado visitó y dibujó Roma (figs. 2 y 3 ), sus calles, iglesias, galerías, museos y realizó un trabajo sobre el Campidoglio y otro sobre la reconstrucción del puerto neroniano de Anzio para los envíos obligatorios de primer y segundo año de pensionado, combinando su estancia con algunos viajes por ciudades del norte de Italia, pasando por Florencia y otras ciudades de la Toscana.

\footnotetext{
* Agradezco a Adolfo Blanco Osborne el acceso al archivo familiar para realizar esta investigación.

${ }^{1}$ Las 166 láminas de la Memoria conservadas en el archivo de su hijo Adolfo Blanco Osborne (AABO), están numeradas en el mismo documento, por lo que se seguirá esta numeración en las notas.

${ }^{2}$ Los planos del examen de oposición para la pensión en Roma se conservan en el Archivo de la Real Academia de Bellas Artes de San Fernando, Pl-45, 46 y 47.
}

Arch. esp. arte, LXXXVI, 341, ENERO-MARZO 2013, 49-76, ISSN: 0004-0428 


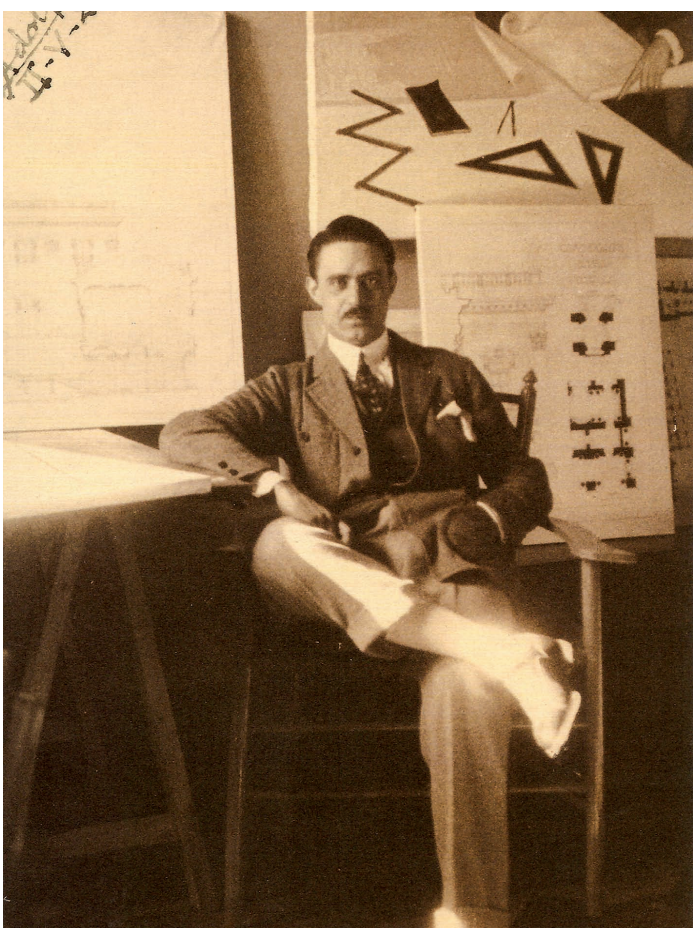

Fig. 1. Adolfo Blanco en su estudio de la Academia, 1925, Archivo Adolfo Blanco Osborne.
En 1926 se le concedió una licencia para viajar a España a ver la Exposición Nacional de Bellas Artes donde había expuesto los trabajos sobre el Campidoglio, para en julio de 1926, emprender el viaje que el reglamento de la Academia de España en Roma de 1913 obligaba hacer a sus pensionados a Grecia y Egipto $^{3}$.

Antes de embarcarse hacia Atenas visitó el norte de África ${ }^{4}$ y de allí a Constantinopla, Praga, Viena y Venecia. En diciembre de 1926, Adolfo Blanco, volvió a Roma para iniciar el trabajo obligatorio de tercer año de pensión que constaba de una memoria teórico-científica sobre una de las cuestiones del debate arquitectónico en Europa. Su propósito fue el realizar un estudio sobre el "Urbanismo Moderno", pero el estipendio que le designaba la Obra Pía ${ }^{5}$ para los viajes no era suficiente para realizar este trabajo. Decidió entonces solicitar una subvención a la Junta de Ampliación de Estudios, que le concedió, en la sesión celebrada el 26 de enero de 1927, la pensión para dedicarse a estudios de Urbanismo en Francia, Inglaterra y Alemania.

El objetivo de la JAE y por lo que concedía estas becas era:

"Situar la universidad y la ciencia españolas en el nivel europeo, solucionando el abandono de la formación del profesorado, de las condiciones de los alumnos y de las dotaciones científicas en las que se encontraba. Las pensiones de la JAE junto con las de la Academia constituían el primer eje de actuación. Enviar a unos cuantos jóvenes a formarse en los semilleros europeos más selectos no hubiese servido de mucho si a su regreso no encontraban unos centros de trabajo apropiados donde continuar su desarrollo, y difundir lo aprendido"6.

El trabajo no lo elaboró en los seis meses de subvención que le concedió la Junta, sino que era, en parte, fruto de los cuatro años de pensión en la Academia de España en Roma. El estudio sobre las ideas modernas del Urbanismo constituyó el resumen de los intereses con que Blanco había llegado a Roma. Desde enero de 1924, fue recogiendo datos sobre el urbanismo de las regiones italianas que iba recorriendo. Sus apuntes de viaje estaban centrados en este aspecto y así, en los cuatro años, reunió información de las ciudades más significativas de Oriente y Occidente, recorriendo Argelia, Marruecos, Túnez, Yugoslavia, Hungría, Austria, Suiza y Francia; Bélgica, Alemania e Inglaterra.

\footnotetext{
3 Archivo de la Real Academia de España en Roma (ARAER), Comunicaciones Oficiales, Caja 89.

${ }^{4}$ En el informe que redacta el director el 19 de agosto de 1926 se detalla el trayecto que realizó el pensionado -Puerto de Brindisi, Atenas, Constantinopla-. ARAER, Comunicaciones Oficiales, Caja 89.

${ }^{5}$ Institución encargada de sostener económicamente a los pensionados en la Academia de España en Roma.

${ }^{6}$ RiBAgORDA, 2009; 152.
} 


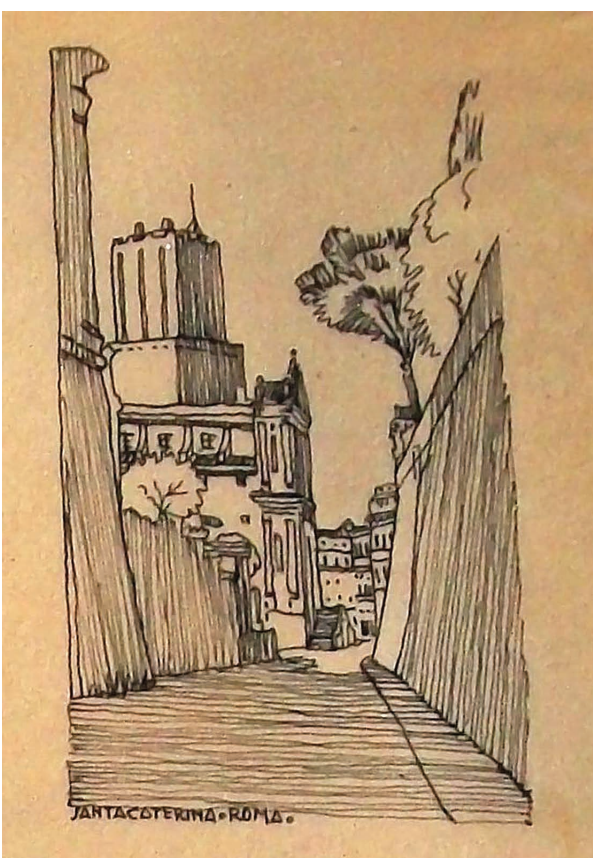

Fig. 2. Adolfo Blanco, Via Santa Caterina, Roma, 1924, Memoria sobre el Urbanismo Moderno, F. 113, AABO.
La "Memoria sobre las ideas modernas del Urbanismo" la presentó como envío obligatorio de tercer año de pensionado y como justificación de la beca concedida por la JAE. La "Memoria" hoy está lamentablemente desaparecida, conservándose una carpeta con los dibujos que ilustraban el texto, en poder de su hijo Adolfo Blanco Osborne, tal y como describen los documentos del Archivo de la Academia de España en Roma que debía contener el trabajo de tercer año de pensión ${ }^{7}$.

Este estudio debió suponer una novedad para la historiografía del Urbanismo ya que las publicaciones y estudios más relevantes y de mayor envergadura de historia del urbanismo llegaron casi cincuenta años más tarde, por lo que estas reflexiones e imágenes, constituyen un repertorio privilegiado y del todo moderno en su tiempo.

El término de "moderno" que Blanco utiliza en el título de este trabajo, se empezó a utilizar entonces al hablar de "modernidad". Un proceso estrechamente ligado al desarrollo de la industrialización y la extensión de las ciudades ${ }^{8}$, que fueron perfilando un nuevo tipo de sociedad, y que son las zonas en las que el pensionado español se detiene en este trabajo.

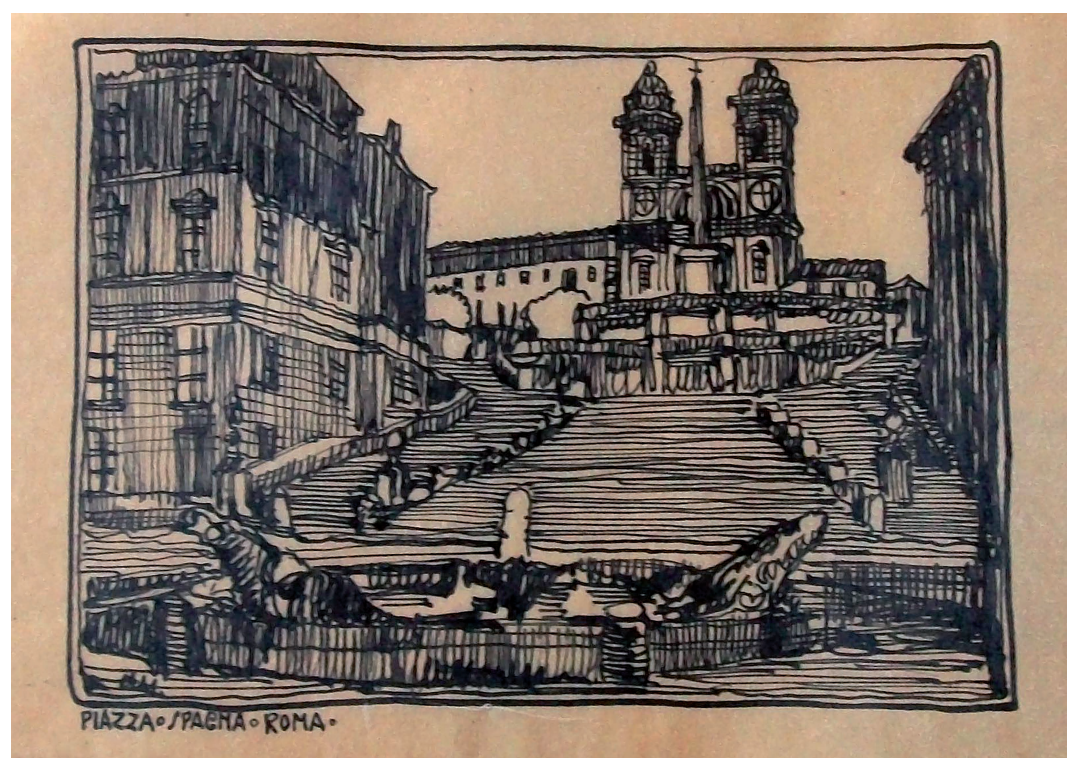

Fig. 3. Adolfo Blanco, Piazza di Spagna, Roma, 1925, Memoria sobre el Urbanismo Moderno, F. 161, AABO.

\footnotetext{
${ }^{7}$ ARAER, Comunicaciones Oficiales, Caja 89.

${ }^{8}$ RibAGORDA, 2009; 15.
} 


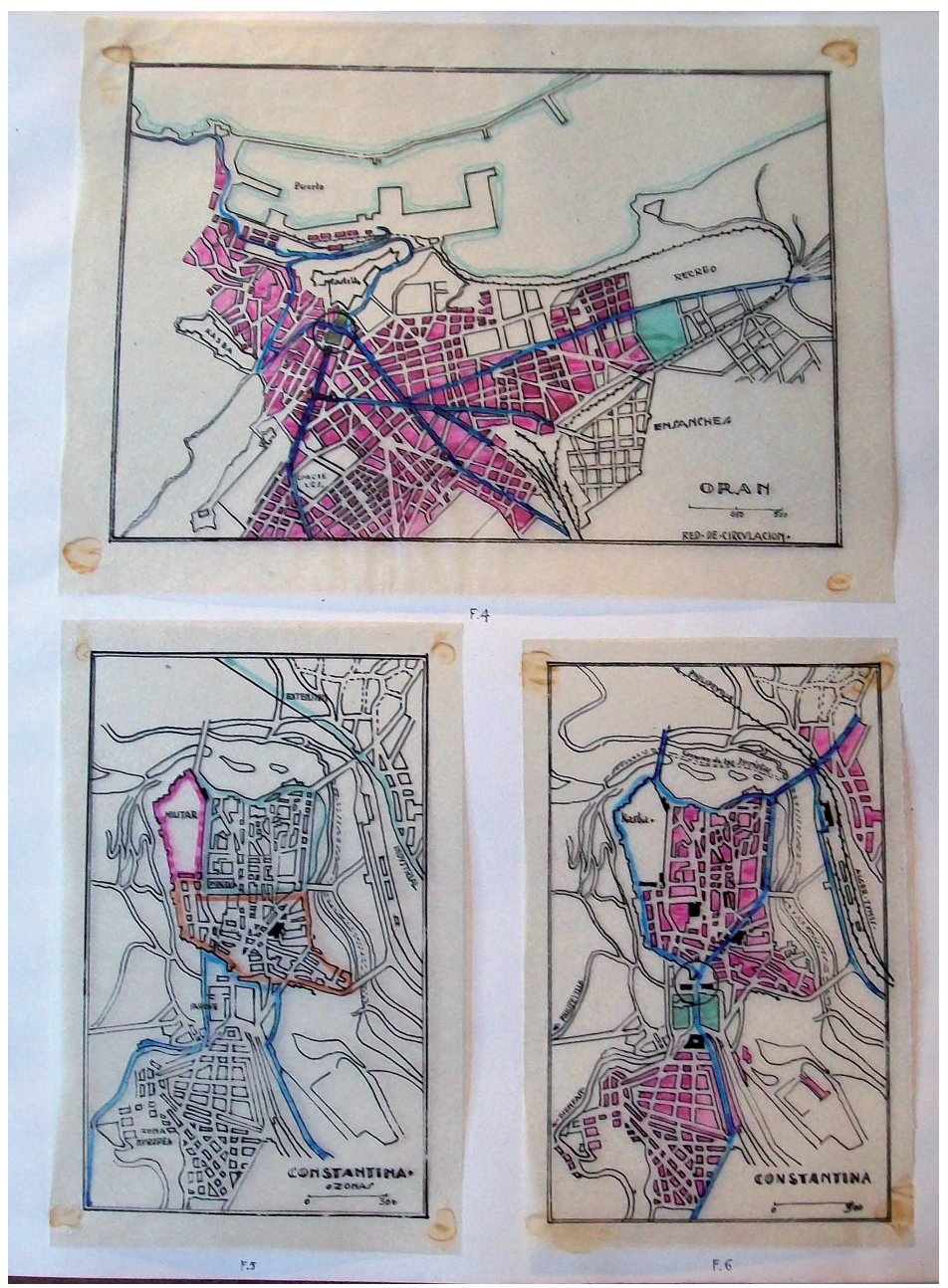

Fig. 4. Adolfo Blanco, Estudio de Oran y Constantina, 1927, Memoria sobre el Urbanismo Moderno, F. 4,5 y 6, AABO.

Antes de llegar a París quiso realizar un segundo viaje a Oriente y a diversas capitales de Euro$\mathrm{pa}^{9}$. Pasó por el norte de África, Grecia y Constantinopla, viaje que duró aproximadamente dos meses, ya que en el mes de marzo estaba matriculado en el curso de Urbanismo de la Sorbona al que le interesó asistir por ser estos estudios los más completos y modernos que en Europa se impartían en este momento ${ }^{10}$.

En Argelia, dibujó los planos de Argel ${ }^{11}$, Orán y Constantina (fig. 4). En la primera, se interesó por las zonas verdes de la ciudad y las vías que a ellas le conducían, señalando con ello la red de penetración a la ciudad antigua. De Orán estudió la red de circulación y la unión de la ciudad

\footnotetext{
${ }^{9}$ Informe del director de la Academia con fecha de 23 de enero de 1927, ARAER, Comunicaciones Oficiales, Caja 89.

${ }^{10}$ Informe del director de la Academia del mes de Mayo de 1927, ARAER, Comunicaciones Oficiales, Caja 89.

${ }^{11}$ Plano de Argel: red de penetración en la ciudad antigua, AABO, F. 2.
} 
antigua con el ensanche. En Constantina, separó los dos núcleos de población más antiguos de la ciudad y realizó dos propuestas de circulación; una que respetaba el núcleo histórico y la otra, que rodeaba el centro con un esquema tomado del desarrollado en la ciudad de Filadelfia que dibujó en la memoria junto a la de Constantina.

En Marruecos, Casablanca era uno de los lugares que mayor transformación sufrió cuando fue protectorado francés, multiplicándose extensamente. La propuesta de Blanco en esta población iba dirigida a una reforma interna de la zona que circunda la ciudad antigua. Al igual que en la ciudad argelina, en Casablanca, dividió la ciudad en zonas por antigüedad, desde la ciudad medieval hasta la zona industrial ${ }^{12}$.

En Rabat, fijó su atención en el Sector de Bou Regreg, una zona nueva urbanizada entre el río y la red Ferroviaria ${ }^{13}$. En Kenitra dibujó el barrio de la Maamora, cuyo trazado urbano mucho tenía que ver con el del Capitolio en Washington ${ }^{14}$. A continuación visitó y dibujó Petit Jean y Mechra Bel Ksiri ${ }^{15}$. En Fez, completó el trazado de la zona europea de la ciudad, cercana al hipódromo y circundada por la carretera que unía Tánger con Fez ${ }^{16}$. En Meknés hace lo mismo, terminando de trazar la zona alejada de la Medina que había sido comenzada a trazar por los ingenieros franceses. Para Marrakesh, en cambio, los dos núcleos de la zona europea están proyectados cerca de la zona industrial de la ciudad y de forma radial abriéndose en abanico ${ }^{17}$.

Para estudiar la ciudad de Túnez utilizó la misma metodología que para Constantina. Le interesaba reflexionar sobre la red de penetración en la ciudad antigua y para ello dividió en diversas zonas y dibujó la red de carretera que circundaba el casco histórico sin atravesarlo ${ }^{18}$. Lo mismo hizo en Sousse, última de las ciudades que visitó y dibujó en el norte de África ${ }^{19}$. Desde allí se embarcó para Atenas donde se preocupó por dibujar la red viaria existente en la Antigüedad para después señalar la moderna red de circulación con largas avenidas que unían las distintas zonas de la ciudad, en contraste con las sinuosas y complicadas vías que ordenaban la antigua Atenas ${ }^{20}$. El puerto del Pireo, sin embargo, tenía su red viaria antigua con una ordenación cuadrangular que en nada se asemeja a la metrópoli ${ }^{21}$.

En Bulgaria, visitó Sofía y dibujó la red de circunvalación moderna trazada por Gutkind y que ya se aprecia en las planimetrías de $1879^{22}$ (fig. 5). En un segundo plano de Sofía indicó, dibujadas, las triangulaciones de las zonas que podían servir para el ensanche de la ciudad, cercanas a la zona industrial. Continuó el viaje por Serbia centrándose en la ciudad de Belgrado y en Hungría, Budapest, ciudades que estudió en dos planos, en los que señaló la red de circulación, en uno y la división en zonas de la ciudad, en el segundo ${ }^{23}$. Remontando el curso del Danubio observó la urbanización de sus riberas y el acceso a las distintas zonas de la ciudad.

En Viena, Blanco analizó las influencias de los estudios del alemán Camillo Sitte, director de la Escuela Imperial y Real de Arte Industrial, quien dotado de una importante formación historicista había publicado en 1889 un obra titulada Der Städtebau nach seinen Künstlerischen Gründsätzen,

\footnotetext{
${ }^{12}$ Casablanca, AABO, F. 10-12.

${ }^{13}$ Rabat, AABO, F. 15.

${ }^{14}$ Kenitra, AABO, F. 16.

15 Via Petit Jean y Mechra Bel Ksiri, AABO, F. 17 y 18.

${ }^{16} \mathrm{Fez}$, AABO, F. 19 y 20.

17 Marrakech, AABO, F.23.

${ }_{18}$ Tunez, AABO, F. 24-26.

${ }_{19}$ Sousse, AABO, F. 27-28, 31 y 33

${ }^{20}$ Atenas, AABO, F. 29, 30 y 34.

${ }^{21}$ Pireo, AABO, F. 32 y 35.

${ }^{22}$ Cuneo, 1986; 383.

${ }^{23}$ Belgrado y Budapest, AABO, F. 40 y 41; F. 42-44.
}

Arch. esp. arte, LXXXVI, 341, ENERO-MARZO 2013, 49-76, ISSN: 0004-0428 


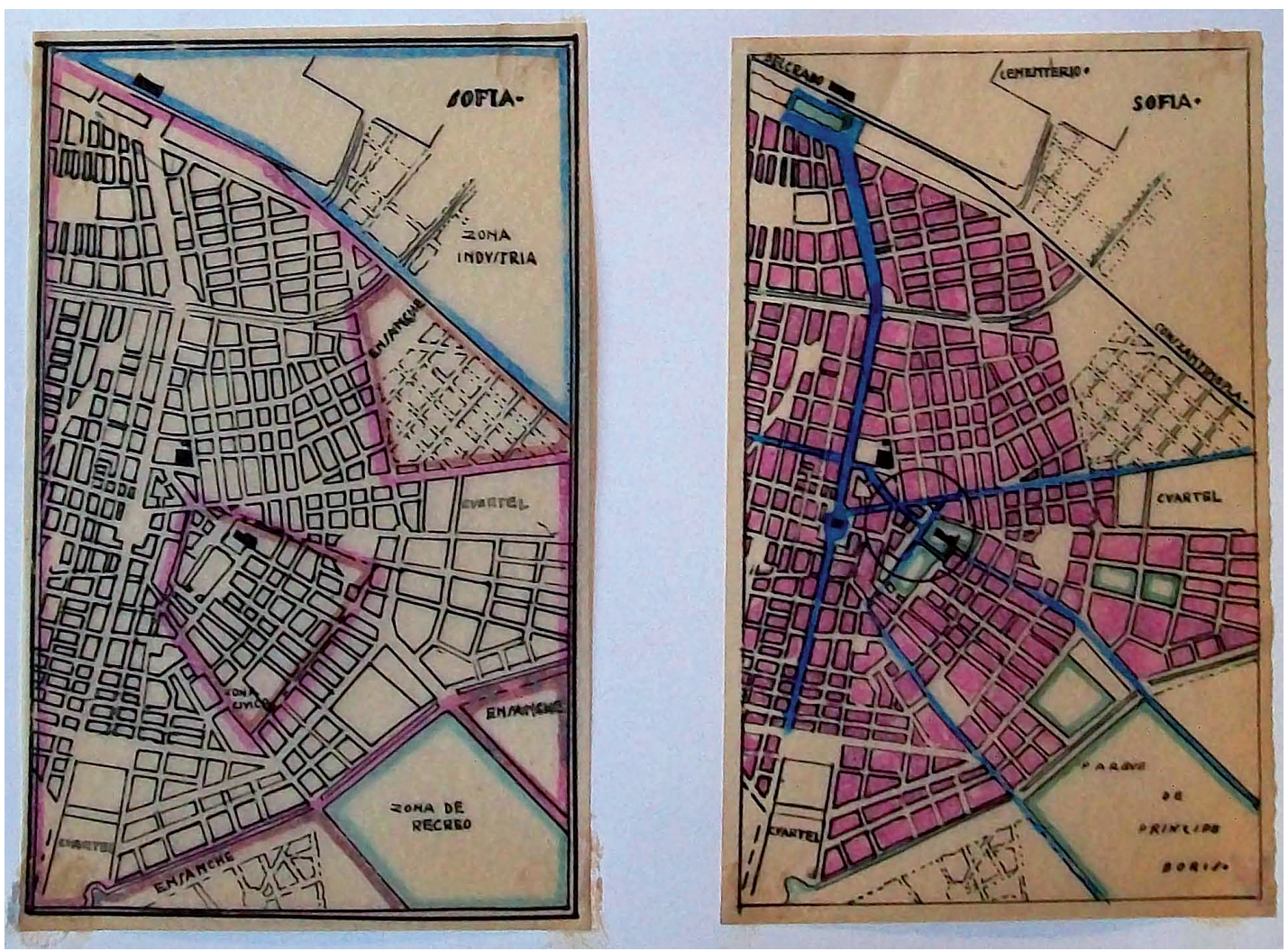

Fig. 5. Adolfo Blanco, Planimetrías de Sofía, 1927, Memoria sobre el Urbanismo Moderno, F. 36 y 37, AABO.

en la que analizaba minuciosamente las características de la ciudad medieval, pretendiendo un modelo de desarrollo basado sobre los mismo principios de composición y de viabilidad ${ }^{24}$. Su contribución puede resumirse en una serie de principios inmediatamente aplicables a una escala espacial reducida que, ya para Giedion, resultaba del todo inadecuada para afrontar los problemas de la escala metropolitana (figs. 6 y 7 ).

Sobrepasando las fronteras austriacas recorrió algunas ciudades y pueblos suizos como Rothenbourg, Berna o Buttstädt, ciudades de las que se conservan sus apuntes de viajes (figs. 8 y 9 ). Otras poblaciones que lindaban con Francia también fueron objeto de su estudio. En todos ellos corregía con sus anotaciones el trazado existente: Dun sur Mouse, Maurupl, Domévre, Apremont, Pinon, Sassey, Chappy, Marbotte, Clermont, Revigny, Vaucourt, Halloville, Montigny, Embermenil, Strasbourg y Reims, donde estudió la ciudad jardín de la Maison Blanche comparándola con la ciudad jardín Aniene de Roma, en la que se inspiran los edificios que ocupan una manzana completa y dibujan el trazado de las calles que conducen a la plaza principal del centro urbanizado ${ }^{25}$ (fig. 10).

En Roma había comenzado a surgir en 1919 el primer núcleo de habitación en el barrio de Montesacro a través de una iniciativa del comité de la Ferroviaria del Estado, la ciudad Aniene,

\footnotetext{
${ }^{24}$ SiCA, 1978; 39.

${ }^{25}$ Reims y la ciudad Aniene, AABO, F. 69 y 70.
} 


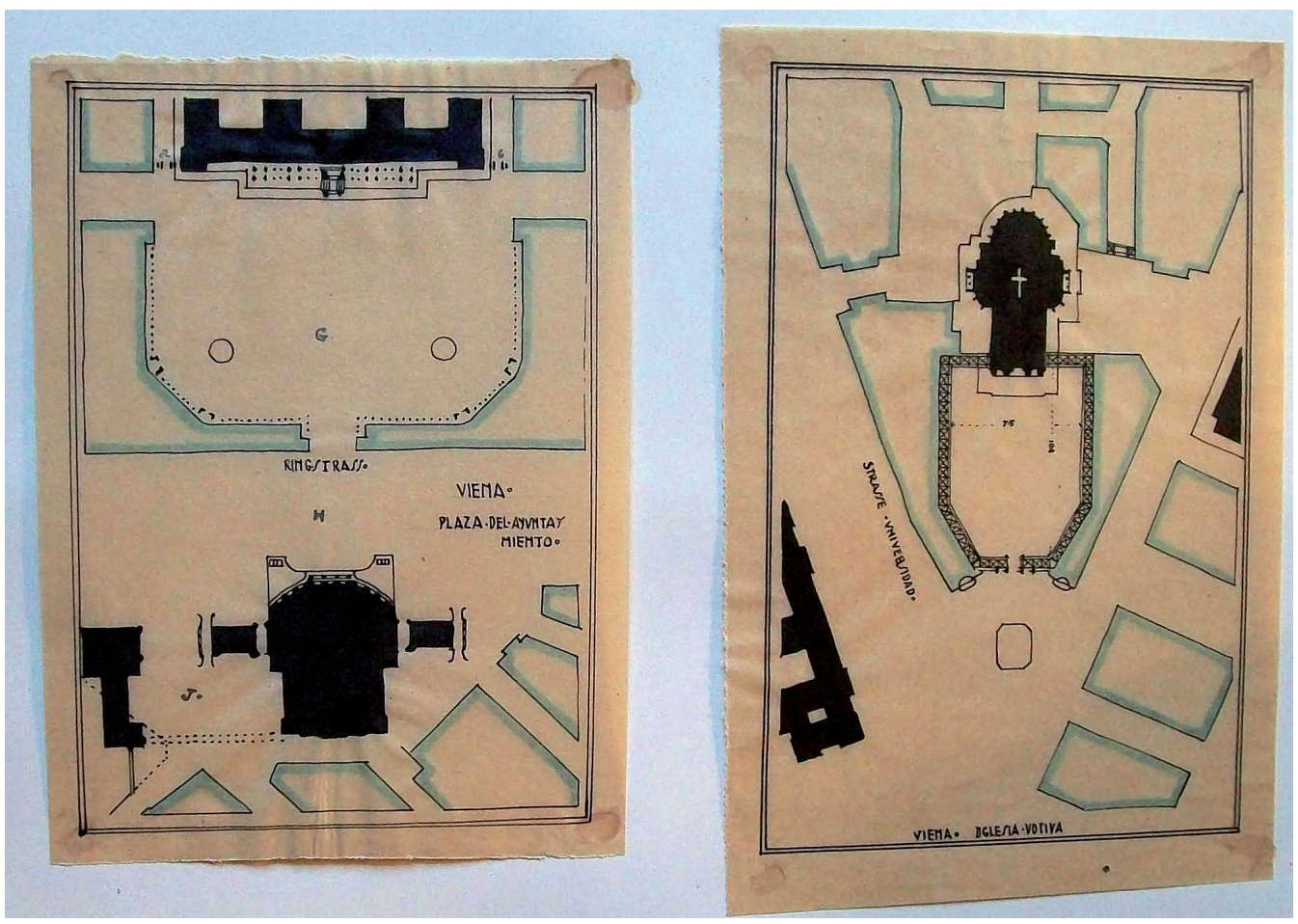

Fig. 6. Adolfo Blanco, Proyecto para la ordenación de la zona de la Votivkirche y del Rathaus de Viena, copia del estudio de Camillo Sitte, 1927, Memoria sobre el Urbanismo Moderno, F. 47 y 48, AABO.
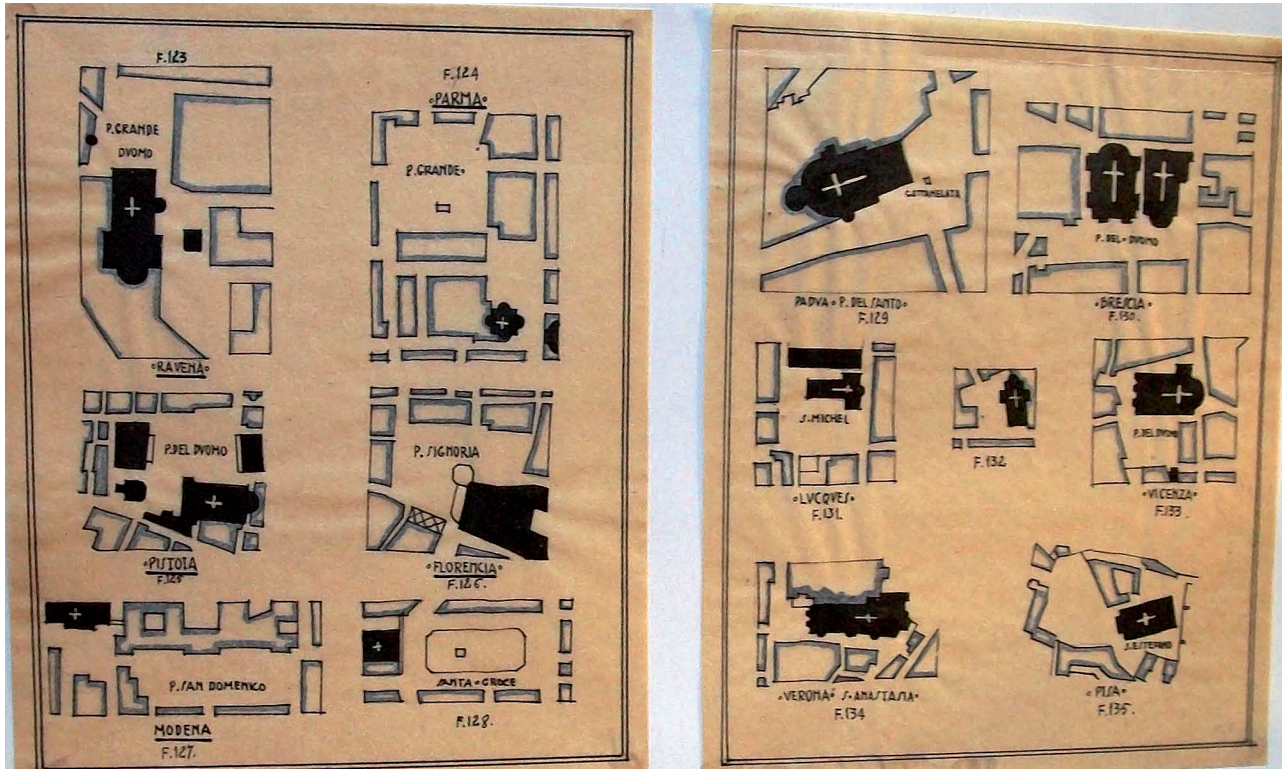

Fig. 7. Adolfo Blanco, Proyectos de ordenación de algunas ciudades italianas, propuestas de Camillo Sitte, 1927, Memoria sobre el Urbanismo Moderno, F. 123-135, AABO.

Arch. esp. arte, LXXXVI, 341, ENERO-MARZO 2013, 49-76, ISSN: 0004-0428 


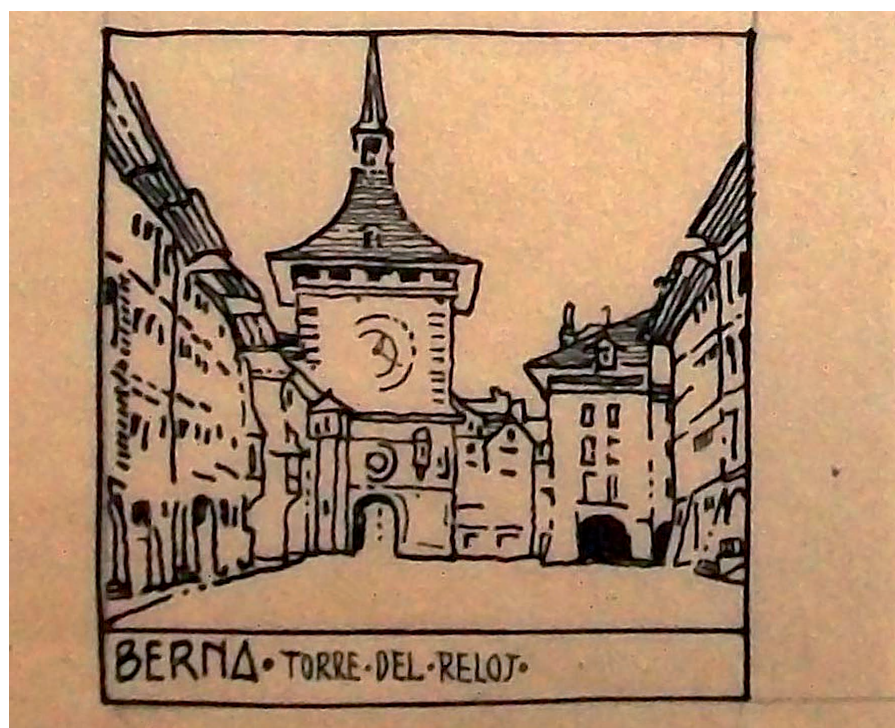

Fig. 8. Adolfo Blanco, Torre del Reloj, Berna, 1927, Memoria sobre el Urbanismo Moderno, F. 165, AABO.

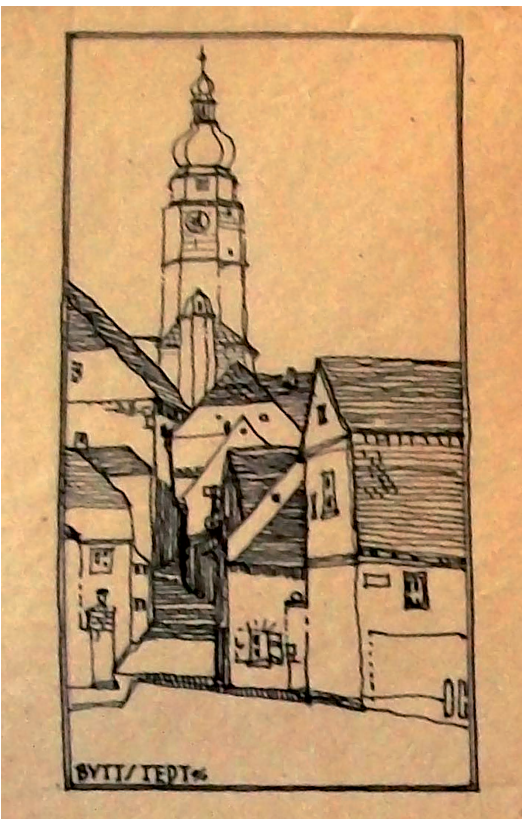

Fig. 9. Adolfo Blanco, Buttstept, 1927, Memoria sobre el Urbanismo Moderno, F. 108, AABO. que seguía el modelo inglés que había creado Howard, conocido por la publicación en 1898 de Gardens cities of tomorrow. El sentido último de la propuesta de Howard, residía, según la opinión de Benedetto Gravagnuolo, en una mediación pacífica entre los dos imanes contrapuestos de la ciudad y del campo, esto es, en la invención de un tercer imán capaz de asumir los requisitos de los otros dos (las ventajas higiénicas del hábitat rural y la red de intercambios sociales del hábitat urbano) ${ }^{26}$.

La ciudad jardín era una propuesta como solución válida para eliminar los slums ${ }^{27}$ inhabitables de las periferias industriales y para utilizar terrenos a bajo precio y gozar de la vida del campo sin renunciar a la ciudad. Nace con ello en las ciudades una clase media que hasta entonces era inexistente. Howard intentó evitar lo que consideraba el "error" de los pensadores utópicos para defender el derecho individual a la posesión de un hogar y un trozo de tierra, aunque a él mismo se le acusó de utópico en su teoría sobre las ciudades del mañana ${ }^{28}$.

El esquema general de la ciudad jardín era un conjunto de anillos concéntricos cortados por seis ejes radiales. En el centro un gran vacío, el parque de la ciudad, rodeado por el primer círculo de los edificios públicos; después una

\footnotetext{
${ }^{26}$ Gravagnuolo, 1998; 78.

${ }^{27}$ Barrios pobres de las ciudades.

${ }^{28}$ Gravagnuolo, 1998; 80.
} 


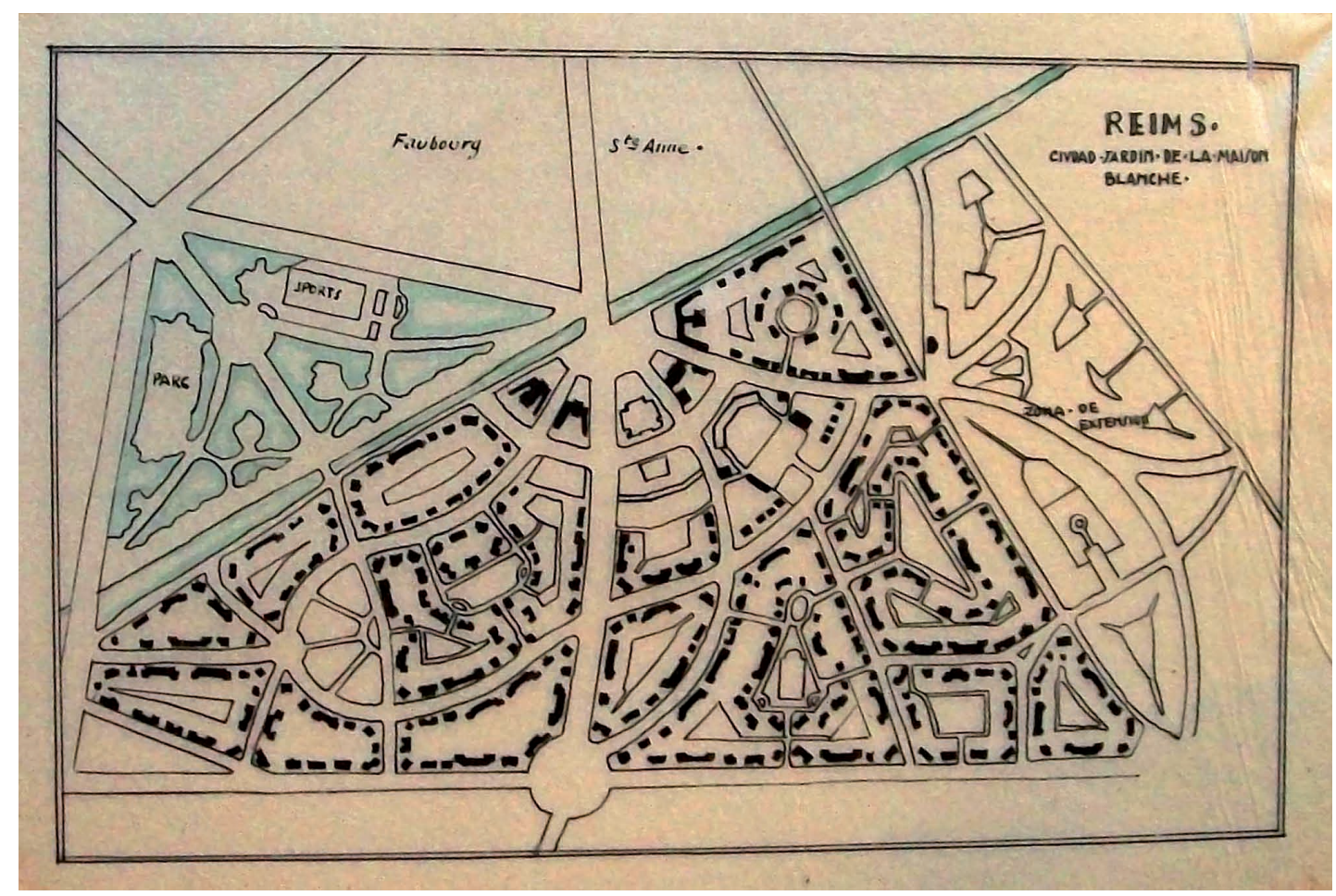

Fig. 10. Adolfo Blanco, Estudio de Reims, 1927, Memoria sobre el Urbanismo Moderno, F. 69, AABO.

banda anular de verde preparado para actividades deportivas, con un Palacio de Cristal, lugar de intercambios sociales y comerciales, además de jardín de invierno evocador del inolvidable Palacio de Paxton; siguen unas avenidas circundadas de cottages, con el círculo medio dominado por una gran avenida, edificada con dos largas cortinas de crescents; finalmente, en el exterior, la línea ferroviaria de circunvalación y las fábricas. Para materializar la idea, funda en 1899 una Garden City Association y, en 1904, da comienzo la construcción de Lechtworth, la primera ciudad-jardín, que Adolfo Blanco visitó en ese verano de 1927 (figs. 11 y 12).

Durante su estancia en París, tanto Blanco ${ }^{29}$ como su compañero García Mercadal, aprovecharon para integrarse y conocer las manifestaciones artísticas que en París se desarrollaron en los años 20. El Art Decó la expresión más extendida entonces, dejó su huella tanto el diseño como la proyección de Blanco de estos años. Y fue entonces cuando, junto a Mercadal, Blanco tuvo ocasión de conocer a Le Corbusier.

Múltiples son los diseños y cuadernos de dibujo que conserva su hijo que reflejan su dominio de la línea y la expresividad que caracterizan su estilo y que se conjugaban con soltura en la personalidad del pensionado español. Desde marzo hasta el verano, revisó sus apuntes de viaje y preparó todas las láminas para incorporarlas al envío de tercer año de pensionado. El 2 de julio de

${ }^{29}$ Instalado en el número 8 de la Rue Sedillot, junto a la Torre Eiffel y el Champ de Mars, donde permaneció hasta julio de ese año.

Arch. esp. arte, LXXXVI, 341, ENERO-MARZO 2013, 49-76, ISSN: 0004-0428 


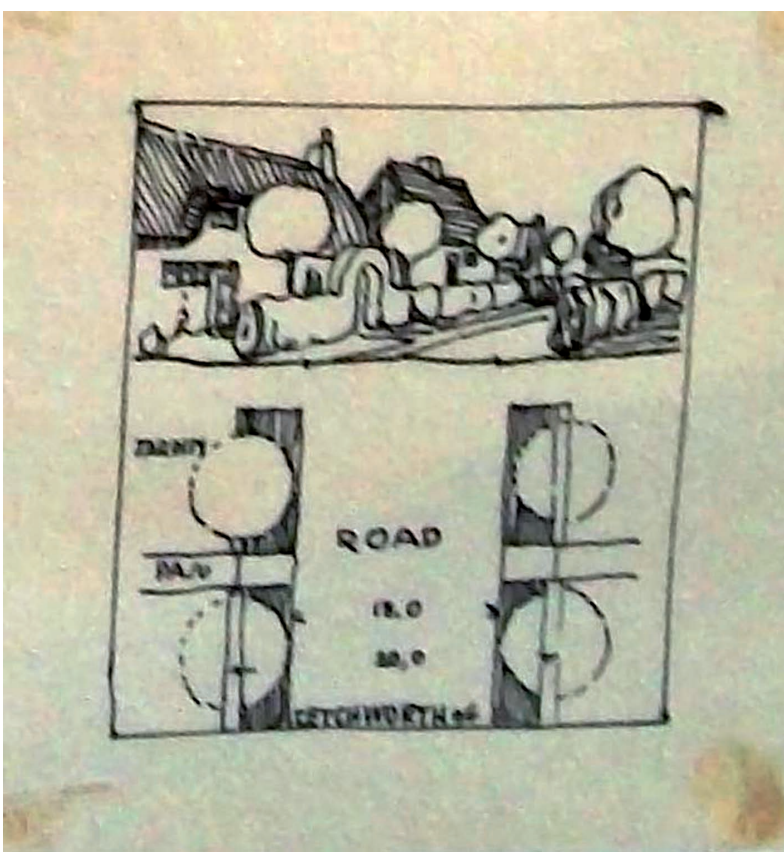

Fig. 11. Adolfo Blanco, Planta y perspectiva de Letchworth, 1927, Memoria sobre el Urbanismo Moderno, F. 118, AABO.
1927 había entregado ya el trabajo y fue juzgado por el tribunal constituido en la Academia de San Fernando ${ }^{30}$.

Además de la memoria escrita y los dibujos, debió de entregar seis maquetas de las que nada dice el acta del envío, pero de la que aparece su noticia en el expediente personal de pensionado del Ministerio de Asuntos Exteriores. Este documento dice así "El 10 de diciembre de 1927 dice Blanco de haber retirado del Ministerio de Estado, tres de las seis maquettes que constituían su envío de tercer año"31.

Una vez entregado este envío del tercer año de la pensión, viajó a Inglaterra, donde recorrió varias de las ciudades satélites de Londres (fig. 13) para conocer los lugares donde nació la tipología de las ciudades jardín. Su programa de viajes estuvo orientado a conocer las ciudades y propuestas de Raymond Unwin que había conocido a

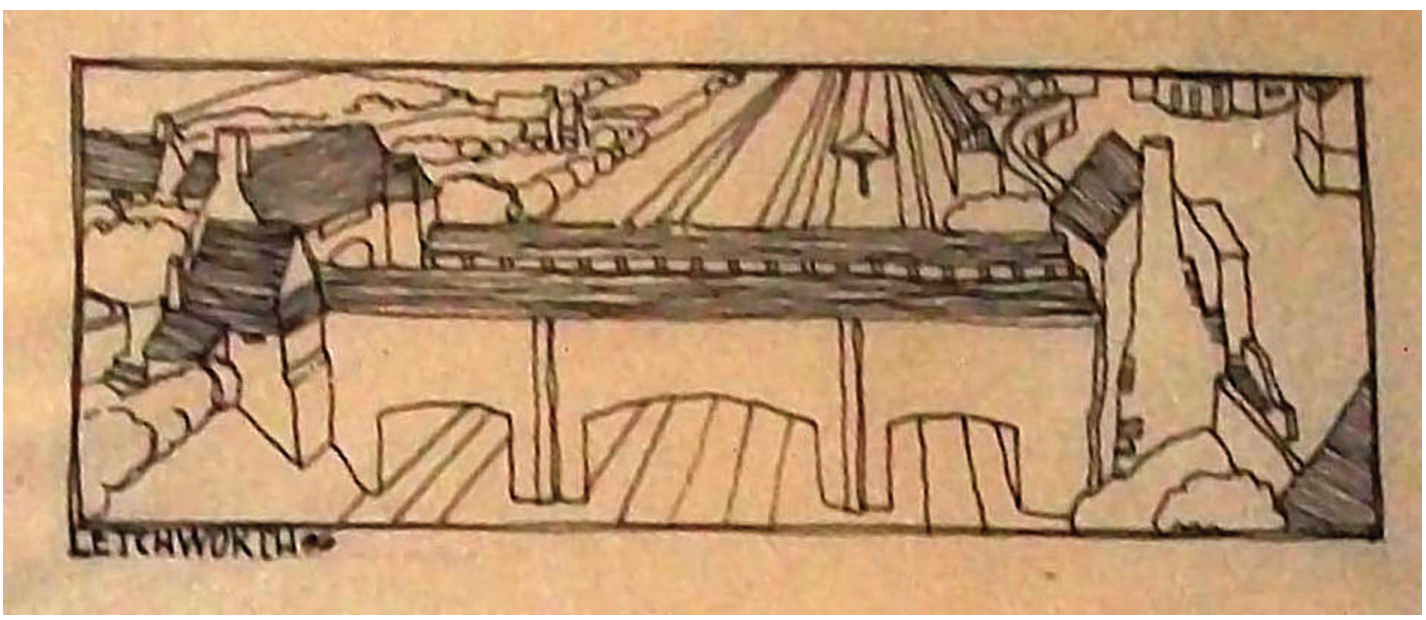

Fig. 12. Adolfo Blanco, Planta y perspectiva de Letchworth, 1927, Memoria sobre el Urbanismo Moderno, F. 119, AABO.

${ }^{30}$ Tribunal compuesto por Manuel Zabala y Antonio Flórez nombrados por el Ministro de Estado; Manuel Aníbal Álvarez, Juan Moya y Luis Bellido designados por la Real Academia de Bellas Artes de San Fernando.

31 AMAE, expediente personal, PG 116, exp. 21946. 
través de las revistas de Arquitectura de la época. Visitó Dunster, Somersetshire, Bristol, Hampstead, Letchworth y Botton, entre otras. El proyecto de Letchworth y Hampstead había sido encargado a Unwin y a Barry Parker y el de Hampstead con una pequeña reelaboración de Lutyens. En este caso, con la voluntad de crear la imagen del pueblo rural que comunicara un sentido de tranquilidad visual, de confort habitacional y de enlace con los valores de la tradición. Representaba, en suma, el paso de la utopía antiurbana de Howard a una más realista y avisada estrategia urbana. Su programa había sido que las personas de todas las clases y todas las categorías de renta puedan habitar allí y que los disminuidos fuera bienvenidos. Pero, en la práctica, Hampstead se convirtió en pocos años en un núcleo exclusivo y refinado de las clases acomodadas que buscaban un refugio-jardín en el entorno inmediato de Londres.

Blanco se incorporó por dos meses al estudio londinense de "Adehesad y Ramsey", arquitectos que definieron a Adolfo Blanco en su certificado de trabajo como "excelente dibujante y trabajador incesante, con gran empeño en el conocimiento de los métodos de organización de las ciudades inglesas" 32 . Esta última estancia sirvió para justificar el buen aprovechamiento de la subvención concedida por la Junta de Ampliación de

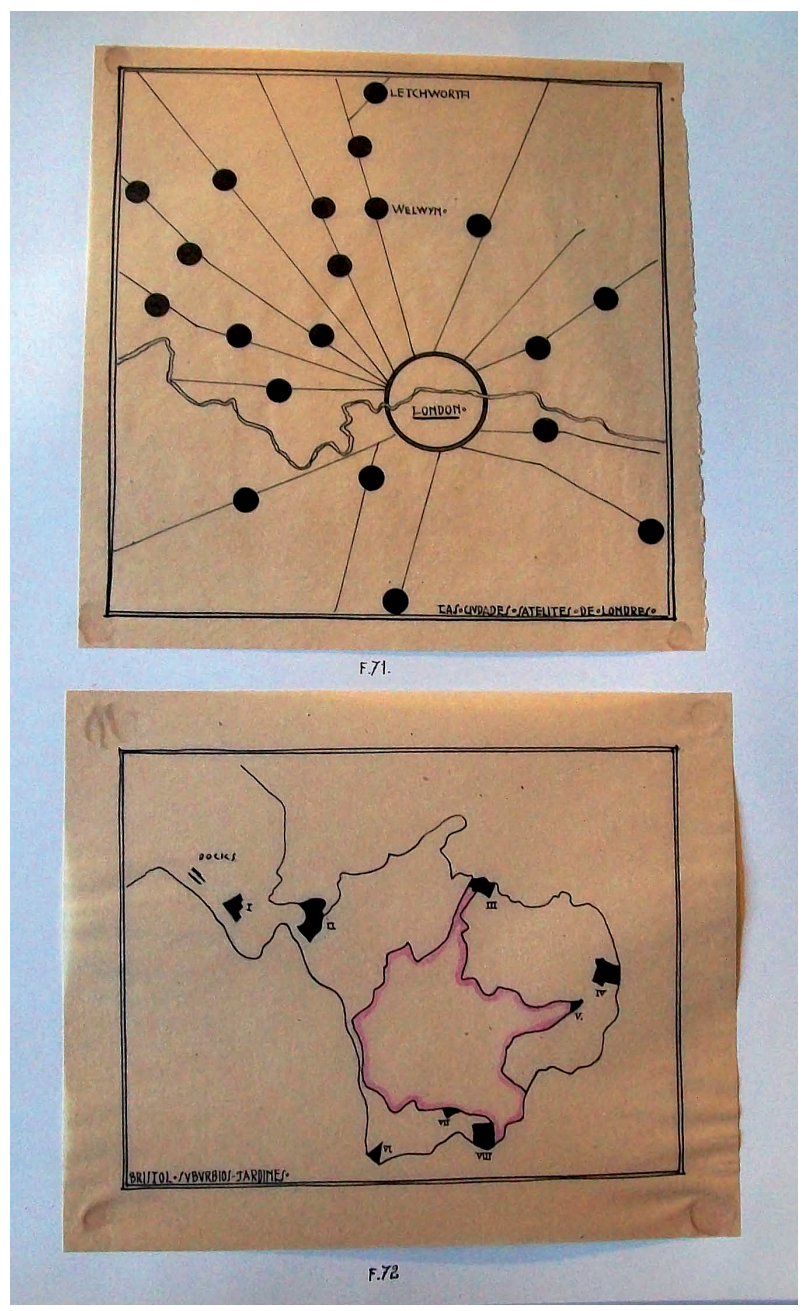

Fig. 13. Adolfo Blanco, ciudades satélite, Londres, 1927, Memoria sobre el Urbanismo Moderno, F. 71 y 72, AABO. Estudios, viéndose coronada por la $\mathrm{Ca}$ lificación Honorífica con la que fue evaluado el trabajo por los académicos del Tribunal de los trabajos de pensionado de la Academia de España en Roma.

A su regreso a España, una vez finalizada su pensión a fines del año 1927, fue nombrado Profesor Auxiliar de la asignatura de Proyectos en la Escuela Técnica Superior de Arquitectura de Madrid, en la que obtuvo la plaza de Catedrático Numerario en 1945 y director de la misma en 1966. Entre los muchos cargos que ocupó en las administraciones públicas del Estado, destacó su labor como Arquitecto Municipal de Madrid, desde 1933, donde llevó a cabo la dirección de más de medio centenar de obras, buena parte de ellas relacionadas con el plan de ensanche de

${ }^{32}$ Certificado remitido por Adehesad, arquitecto y profesor de urbanismo de la RIBA, el 3 de noviembre de 1927, $\mathrm{AABO}$

Arch. esp. arte, LXXXVI, 341, ENERO-MARZO 2013, 49-76, ISSN: 0004-0428 
la ciudad de Madrid, como por ejemplo el proyecto de la colonia de Nuestra Señora de los Ángeles de Madrid con 640 viviendas, casas para maestros y grupos escolares o la Colonia de San Francisco Javier en el Puente de Vallecas con 420 viviendas, para lo que fueron determinantes la observación directa y los trabajos realizados en los diversos viajes, fruto de su pensión académica.

\section{BIBLIOGRAFÍA}

Blanco, Adolfo, 1975, El Capitolio Romano, Ed. Servicio de Publicaciones de la Fundación Universitaria San Pablo (CEU), Madrid.

Carvajal Ferrer, Javier, 2003, "Recuerdos pedagógicos: el arquitecto Adolfo Blanco", en Roma y la tradición de lo nuevo. Diez artistas en el Gianicolo (1923-1927), Catálogo Exposición, Academia de España en Roma-Residencia de Estudiantes, 2003-2004.

Cuneo, Paolo, Storia dell urbanistica. Il mondo islamico, Ed. Laterza, 1986.

Fraticelli, Vanna, 1982, Roma 1914-1929. La città e gli architetti tra la guerra e il fascismo, Roma.

Gravagnuolo, Benedetto, Historia del Urbanismo en Europa, 1750-1960, Ed. Akal Arquitectura, traducción de Juan Calatrava, 1998.

López Valencia, Federico, 1923, El problema de la vivienda en Inglaterra, Ibérica, Madrid.

Moneo, Rafael, "Adolfo Blanco en la lontananza", en Roma y la tradición de lo nuevo. Diez artistas en el Gianicolo (1923-1927), Catálogo Exposición, Academia de España en Roma-Residencia de Estudiantes, 2003-2004, pp. 146-147.

Ribagorda, Álvaro, Caminos de la modernidad. Espacios e instituciones culturales de la Edad de Plata (18981936), Madrid, Ed. Biblioteca Nueva, 2009.

Sica, Paolo, Storia dell Urbanistica. Il Novecento $1^{o}$, Ed. Laterza, 1978.

Fecha de recepción: 20-I-2012

Fecha de aceptación: 16-III-2012 